\begin{tabular}{|c|c|c|}
\hline \multirow{2}{*}{$\begin{array}{l}\text { Cellular Physiology } \\
\text { and Biochemistry }\end{array}$} & \multicolumn{2}{|c|}{ Cell Physiol Biochem 2019;53:121-140 } \\
\hline & $\begin{array}{l}\text { DOI: } 10.33594 / 1000000125 \\
\text { Published online: } 24 \text { June } 2019 \\
\text { Accepted: } 18 \text { June } 2019\end{array}$ & 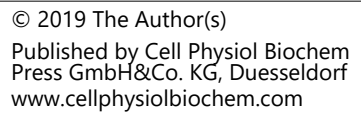 \\
\hline
\end{tabular}

Review

\title{
A Kidnapping Story: How Coxsackievirus B3 and Its Host Cell Interact
}

\author{
Stefan Peischard ${ }^{a}$ Huyen Tran Ho Carsten Theiss $^{b}$ Nathalie Strutz-Seebohm ${ }^{a}$ \\ Guiscard Seebohma \\ aCellular Electrophysiology and Molecular Biology, Institute for Genetics of Heart Diseases (IfGH), \\ University Hospital Münster, Münster, Germany, 'Institute for Anatomy, Department of Cytology, Ruhr- \\ University Bochum, Bochum, Germany
}

\author{
Key Words \\ RNA Virus $・$ Infection $•$ Apoptosis $\bullet$ Myocarditis $•$ Protease
}

\begin{abstract}
Infections with Coxsackievirus B3 and other members of the enterovirus genus are a common reason for myocarditis and sudden cardiac death in modern society. Despite intensive scientific efforts to cure enterovirus infections, there is still no standardized treatment option. The complexity of Coxsackievirus B3's effects on the host cell make well defined studies on this topic very challenging. However, recent publications report newly found effects of CVB3's structural and non-structural proteins on infected cells. For the first time, the viral capsid protein VP1 was shown to have direct influence on the viral life-cycle. By shortening the G0 and the $\mathrm{G} 2$ phase and simultaneously prolonging the $\mathrm{G} 1$ and $\mathrm{G} 1-\mathrm{S}$ phase, the translation of viral proteins is enhanced and the production of viable CVB3 particles is promoted. Coxsackievirus B3's viroporin, protein 2B, was recently studied in more detail as well. Structural and physiological analyses identified two hydrophilic $\alpha$-helices in the structure of $2 B$, enabling it to insert into cellular membranes of host cells. As main target of $2 B$ the endoplasmatic reticulum was identified. The insertion of $2 B$ into the ER membranes leads to an uncontrolled calcium outflow into the cytoplasm. Additional insertion of $2 \mathrm{~B}$ into the cell membrane leads to host cell destabilization and in the end to release of viral progeny. The importance of the Coxsackievirus B3's proteases $2 \mathrm{~A}$ and $3 \mathrm{C}$ in pathogenicity is observed since years. Recently, DAP5 and elf4G were identified as new cleavage targets for protease $2 \mathrm{~A}$. Cleavage of DAP-5 into DAP5-N and DAP5-C changes the gene expression of the host cell and promotes cell death. Additionally, protease $3 \mathrm{C}$ targets and cleaves procaspase 8 promoting the mitochondrial apoptosis pathway and cell death. Recent studies identified significant effects of CVB3 on mitochondria of infected cells. Mouse cardiomyocytes showed decreased activities of respiratory chain complexes I-III and changed transcription of important subunits of the complexes I-IV. A disrupted energy metabolism may be one of the main causes of cardiac insufficiency and death in CVB3 infected patients. In addition to a modified energy metabolism, CVB3 affects cardiac ion channels, KCNQ1 in particular. SGK1, which is an important

Prof. Dr. Guiscard Seebohm Department of Cardiovascular Medicine, Institute for Genetics of Heart Diseases (IfGH), University Hospital Muenster, D-48149 Muenster, Robert-Koch Straße 55 (Germany)

Tel. +49 (0)251/83-58255, Fax +49 (0)251/83-58257, E-Mail guiscard.seebohm@ukmuenster.de
\end{abstract}




\section{Cellular Physiology Cell Physiol Biochem 2019;53:121-140

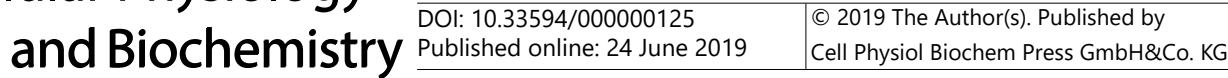 \\ Peischard et al.: CVB3 Host Cell Interaction}

mediator in KCNQ1 membrane insertions, is highly upregulated during CVB3 infections. This results in an increased insertion of KCNQ1 into the cell membrane of cardiac cells. Under stress conditions, this KCNQ1 overshoot may lead to a disturbed cardiac action potential and therefore to sudden cardiac death, as it is often observed in CVB3 infected persons.

(C) 2019 The Author(s). Published by Cell Physiol Biochem Press GmbH\&Co. KG

\section{Introduction}

In modern days we progressively improve our knowledge on how the human body works and how diseases affect us and our society. In the past decades we learned to investigate and conquer severe threats like certain types of cancer, degenerative diseases, bacterial infections and parasites, but virus induced diseases are still difficult to handle and remain challenging in treatment. One reason for this might be the immense diversity in which viruses appear.Viruses appear in all kinds of shapes and ways to infect the human body, which means that there is not just one treatment to cure all of the effects they have on us. Another difficulty in treating virus induced illnesses is the variety of tissues a virus can infect and use for its replication. In the case of the Coxsackievirus genus, it is known that several organs can be affected after infection, for example the gut, heart, pancreas and the neuronal system [1, 2], which can lead to severe organ damage and even death. In the case of Coxsackievirus B3 (CVB3), it was suggested that this virus in most cases is responsible for viral myocarditis, resulting in sudden cardiac death in our modern society. However, the molecular mechanism for this is still insufficiently studied [3]. Although there were approaches to study CVB3 infections in murine models, it is hard to transfer the findings of these studies to humans because of structural and physiological differences between mouse and human tissues. Therefore it would be preferable to investigate the disease on human samples of infected patients like it is done in cancer research or other fields. The problem of doing so, is that CVB3 infections often remain undetected for a long time and only become pathological, when the infection becomes chronic and severe. At this point, an adequate treatment is impossible, and the time for early stage infection observation was long missed [4]. Nevertheless, recently a few research groups were able to observe pathologic effects of CVB3 in human systems.

\section{CVB3 pathogenicity}

The Coxsackievirus B3 genome codes for four structural and 7 non-structural proteins enabling the virus to take over the host cell, start viral replication and promote cell lysis.

Coxsackieviridae belong to the enterovirus genus and to the family of picornaviridae. Within this species Coxsackievirus Type A with 23 different serotypes and Coxsackievirus type B with 6 different serotypes can be distinguished. Infection with Coxsackievirus B3 is the most common reason for viral myocarditis and sudden cardiac death, within the enterovirus genus, with a very malicious disease pattern [5]. Shortly after infection with CVB3 particles, mostly abundant in feces and the intestinal tract, flu-like symptoms appear including fever, sore throat, gastroenteritis and diarrhea. In some cases the acute CVB3 infection can turn into a chronic disease with several different outcomes, depending on the organ that gets infected. Main targets of CVB3 are the heart, resulting in myocarditis, pericarditis and sudden cardiac death and the pancreas, leading to pancreatitis and diabetes-like symptoms [6]. Regarding the infection of the heart, myocarditis and dilated cardiomyopathy are the most common effects of a CVB3 infection [3]. The appearances of this clinical outcome were long-time observed, but the underlying cause for viral-induced myocardial inflammation and infarction was unknown. To understand the pathology of CVB3 one has to have a closer look on the virus structure.

CVB3's genetic information is stored in a small, 7.4Kb long ssRNA, which codes for the structural proteins VP1-VP4 and for 7 non-structural proteins $2 \mathrm{~A}-2 \mathrm{C}$ and $3 \mathrm{~A}-3 \mathrm{D}$, as well as for their precursor dimers $2 \mathrm{BC}, 3 \mathrm{AB}$ and $3 \mathrm{CD}$ [3]. The translation of the ssRNA into 


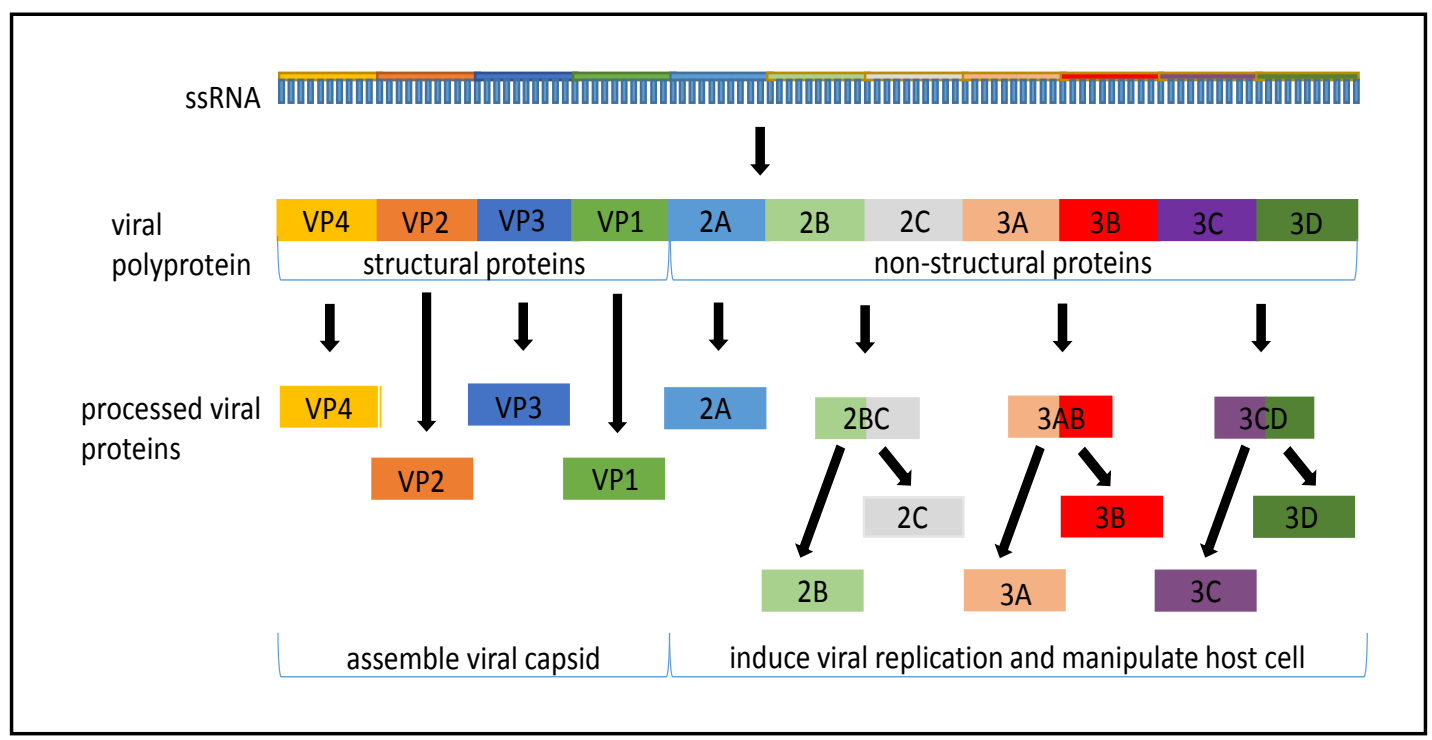

Fig. 1. Organisation of the Coxsackievirus B3 genome. The genetic information of CVB3, stored in ssRNA, is translated into a viral polyprotein containing the primary structure of each of CVB3's structural and nonstructural proteins. The polyprotein is cleaved into viral single proteins and precursor dimers via proteolytic degradation.

functional proteins leads to a single polyprotein in the first step, which is then cleaved by proteases into the single viral proteins. The structural proteins are destined to assemble together in the right manner, to form the virus capsid, whereas the non-structural proteins have the synergetic objective to ensure the production of viral RNA by the host cell and to enable the lysis of cell membranes to release assembled CVB3 particles into the extracellular space (Fig. 1) [6]. This host-cell lysis and cell death can be distinguished into two types which are both induced by CVB3 and other picornaviruses [7]. The first type of cell death is the general apoptosis. The binding of FasL, TNF or TRAIL to the cell death receptors leads to the activation of DISC and to caspase 8 recruitment. Caspase 8 is able to trigger the activation of caspase 3 which leads to DNA fragmentation in the nucleus. Alternatively, caspase 8 activates Bid, which accumulates in the mitochondria and which leads to the release of cytochrome c (CYT c) out of the resulting apoptosome, thus activating caspase 9 and caspase 3 [8]. The second type of cell death, which also plays a crucial role in CVB3 infection is autophagy. Autophagy is characterized by the production of autophagosomes, small membrane clusters or vesicles, which are digested by the host-cell itself. Over time the cell will devour itself and in consequence release viral progeny from the dying cell into the extracellular space which leads to the infection of surrounding tissue [9].

It is commonly suspected that the non-structural CVB3 proteins 2A-3D are responsible for the majority of the pathologic effects which can be observed in infected tissue. The non-structural proteins and their precursors have very diverse, but specialized tasks within the host cell. Two of the most important non-structural proteins, when it comes to pathology, are the viral proteases $2 \mathrm{~A}$ and $3 \mathrm{C}$. These two proteins are responsible for cleavage of the immature viral polyprotein, as well as for the disruption of homeostasis, translation and the cytoskeletal integrity [10]. Protein 2B is associated with the cellular membrane and regulates the production of virus-containing membrane vesicles. Similar to this the proteins $2 \mathrm{C}$ and its membrane associated precursor $2 \mathrm{BC}$ aid production of membrane vesicles in virus replication. The viral polymerase $3 \mathrm{D}$, together with the proteins $3 \mathrm{~A}$ and $3 \mathrm{AB}$, act as viral replication complex to allow the production of viral RNA. Protein 3B, also called VPg, plays an important role in viral replication as well. It binds to the $5^{\prime}$ end of the viral genome and acts as a primer for the viral polymerase to start translation. Without the VPg initiator, the viral replication could not take place and no viral progeny would be produced. The role of the 
structural proteins VP1-VP4 in the manipulation of the host cell or in the replication of the virus itself is almost unknown, but there is some evidence, that the structural proteins play a crucial role within these processes, too [8].

For a long time, knowledge on the replication cycle and the pathogenesis of CVB3 in the human host or in model organisms like mouse was sparse. It was assumed that viral infection and replication generally works via viral docking to the host-cell membrane, uptake of genetic information and self- replication with the help of the host-cells replication apparatus. But as many recent studies show, the scenario is more complex. Viral proteins, non-structural and supposedly structural proteins as well, play a crucial role in viral infectivity and self-replication. This renders the viral life cycle more complex and laborious to study.

\section{The role of VP1 in the disruption of the cell homeostasis and cell cycle}

The viral capsid protein VP1 modulates the cell cycle of the host cell promoting the successful expression of viral proteins and thereby leads to enhanced production of viral progeny.

As a recent target of investigation the structural protein VP1 came into focus, because it seems to play a key role in the CVB3's life-cycle, contrary to early assumptions that it is just a part of the viral protein shell. Back in the early 1990's, a Harvard Medical School research team showed a potential effect of the VP1 capsid protein in on Polyomavirus viral transport and nuclear localization. In their study they were able to demonstrate for the first time that there is a functional localization sequence encoded in the VP1 protein, which enables the VP1 protein to be transported to the cell's nucleus. They designed several VP1- $\beta$-galactosidase fusion proteins and detected their distribution within VERO cells. By screening several fusion proteins containing different sequences of the VP1 protein, Moreland et al. could pinpoint a specific sequence within the VP1 protein, the MAPKRK sequence, which leads to the accumulation of VP1 around the cell's nucleus, where it probably has some effect on viral formation or cell homeostasis. But the exact function of VP1 remained unclear [11].

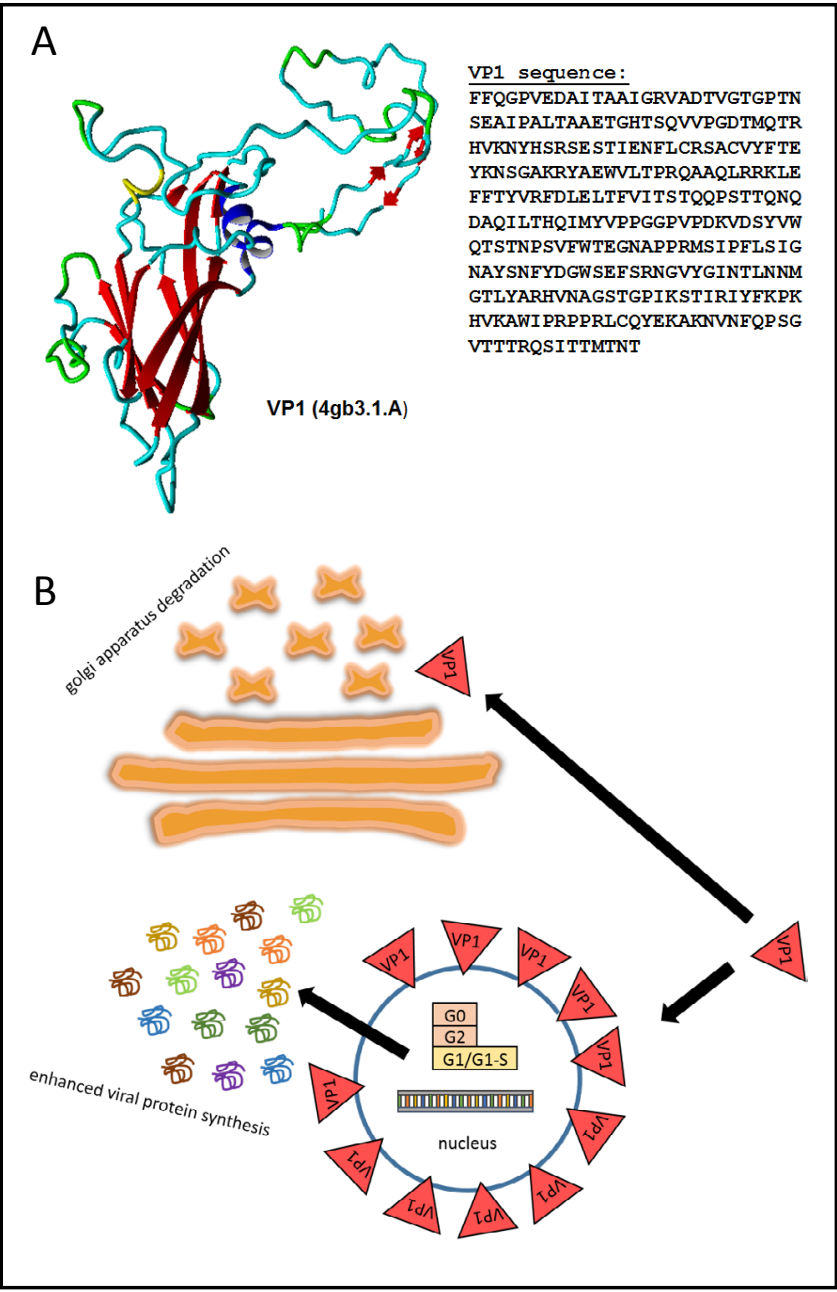

Fig. 2. Role of the structural protein VP1 in the disruption of the cell homeostasis and cell cycle. Structure and function of viral capsid protein VP1. A: 3D Model of VP1. B: Function of VP1 in the host cell. VP1 accumulates in and around the cell's nucleus and changes the cell-cycle process. Furthermore VP1 interacts with the Golgi- Matrix and leads to Golgi degradation. VP1 leads to cell-cycle deregulation elongating the G1/G1-S phase, while the G0-phase and the G2-phase shorten. The cell-cycle deregulation enhances the CVB3 expression. 
Since this study, only small effort was put into the observation of viral capsid proteins in the viral life- cycle until 2012, when a team around Abaitua et al. from the Imperial College London observed the effect of the capsid protein VP1-2 of Herpesvirus [12]. They identified a small sequence in the VP1-2 protein at position 475, leading to the nuclear localization of Herpesvirus VP1-2 in host cells. This sequence was found to be highly conserved in all Herpesviruses and thus must play a crucial role in the virus life-cycle. By creating a small mutation in which just 7 amino acids were replaced within this nuclear localization sequence, the VP1-2 protein was not able to accumulate close to the host-cell's nucleus. To verify the role of VP1-2 in the Herpesvirus life-cycle, Abaitua et al. generated a mutant virus line, VP1-2 $\Delta \mathrm{NLS}$, containing the aforementioned 7 amino acid mutation of VP1-2 and visualized differences in the viral spread and plaque formation [12].

The wild type virus was able to infect several cell lines, like VERO cells and HS30, and replicate within them. This led to expected viral plaques within the cell monolayer and a wide spread of the virus. The mutant virus VP1-2 $\Delta$ NLS was only able to infect complementing cell lines like HS30, while non- complementary ones like VERO cells were unaffected, not showing any viral plaques. This finding leads to the conclusion that the Herpes virus VP1-2 capsid protein plays a role in viral replication and host- cell infection. By observing the localization of the VP1-2 protein in immunofluorescence and in electron microscopy, the team of Abaitua et al. found a high abundance of VP1-2 containing viral capsids and protein fragments in close proximity to the nuclear envelope of the host cells, while cells infected with the virus strain VP1-2 $\Delta$ NLS showed an accumulation of VP1-2 containing capsids around the microtubule organizing center (MTOC). The authors concluded that the Herpesvirus VP1-2 protein is required for successful viral transport of the virus to the host-cell's nucleus and probably aids infection as well. VP1-2 with mutations affecting localization in proximity and correct transport leads to the accumulation at the MTOC, proving that the NLS is actively influencing the nuclear transport of VP1-2 and probably VP1 proteins of other viruses like CVB3 [12].

Regarding the findings of the two groups mentioned before, there is reason to imply that the VP1 capsid protein of CVB3 may be relevant for the life-cycle of CVB3 as well and is not only a viral capsid protein without further functions. Wang et al. addressed this question in 2012 and performed a study on the VP1 protein of CVB3 and its part in viral infection [13]. Wang et al. first transfected HeLa cells with a plasmid expressing the VP1-GFP CVB3 protein and checked for the localization of VP1 in the transfected cells. The VP1 was highly abundant around and in the nuclei of the transfected cells, indicating a specific function of VP1 in this compartment of the cell. To verify this result, clones containing different subsequences of the VP1 protein were generated and transfected into a new set of HeLa cells to check, if a specific region of the VP1 protein is responsible for the perinuclear localization of VP1. The experiment resulted in the detection of a potential nuclear localization sequence (NLS) close to the C-Terminal end of VP1 between amino acid 213 and 275. To localize the responsible element of the nuclear distribution, amino acids within this range were mutated randomly and analyzed for their influence on nuclear localization. The His220Thr amino acid change led to a loss in nuclear localization indicating the necessity of this amino acid for the NLS. Instead of a nuclear localization, the mutant His220Thr localized in a dotted pattern around the nucleus. The screening of different VP1 subsequences transfected into HeLa cells indicated a second sequence responsible for the dotted distribution between Ala72 and Phe106 of the VP1 protein. To explore the role of the VP1 protein in the life-cycle of CVB3, Wang et al. transfected HeLa cells with the wtVP1 and the His220Thr Mutant VP1. They demonstrated that, after 48h of expression, the wtVP1 transfected cells showed a highly prolonged S-Phase and a significantly shorter G2-M Phase. The cells transfected with the His220Thr mutant VP1 showed a milder S-Phase shortening compared to the VP1 expressing group and a normal G2-M Phase (Fig. 2) [13].

This finding proves that the presence and nuclear localization of CVB3-VP1 has a strong effect on the cell cycle of the host cell, which probably also plays a role in the pathogenicity of CVB3 itself. Previous studies imply that CVB3 infected cells produce more viral protein in their 
G1 and G1-S phase, the phase in which the cell grows and reproduces cellular organelles, while viral expression is significantly lower in cells observed in G0 and in G2 phase. A shortening of G2, as verified in this study may lead to a higher production of viral proteins by the host cell resulting in higher reproduction of CVB3 $[14,15]$. Furthermore, the VP1 protein of Coxsackievirus B3 is reported to have an impact on GM130, the golgi matrix protein 180, and pancreatic tissue, leading to pancreatitic phenotypes in mouse models [2]. The roles of the other CVB3 capsid proteins VP2-VP4 are still largely unknown.

\section{CVB3 non-structural proteins and their complex mechanisms}

The role of non-structural proteins in disease development and several general issues of Coxsackievirus infection are mainly solved. However, many questions are still not answered, especially when it comes to the interactions between several non-structural proteins with each other and their interaction with the host cell. The mechanism of viral infection and disease with all its side effects and involved members is so complex, that it is hard to pinpoint a protein or a set of interaction partners for investigation, so that a mechanism of Coxsackievirus infection can be understood completely. The available data leave open questions, which can only be solved by new investigations. Still, recent research faced this challenge and is emerging a general picture of CVB3 infections.

\section{Viroporin 2B is membrane associated and leads to autophagy and changed calcium homeostasis}

The viroporin $2 \mathrm{~B}$, with its hydrophobic $\alpha$-helices, accumulates in the membranes of the endoplasmatic reticulum, which changes the calcium homeostasis of infected cells and promotes autophagy.

CVB3 and its non-structural proteins are seen as the main drivers of cell death and viral replication in which each of the CVB3 proteins plays an important role, from cell cycle regulation and viral replication to apoptosis. Therefore, every non-structural protein fulfills several tasks inside of the host cell, which is necessary due to the narrow genome of CVB3. The role of some CVB3 proteins is understood since long-time, as the role of 3D as viral polymerase of VPg as translation initiation factor. Relatively unknown was the role of the protein $2 \mathrm{~B}$.

It was found that in host cells CVB3-2B is localized mostly within cellular membranes, especially in the membranes of the Golgi apparatus and the endoplasmic reticulum (ER) [16-19]. The membrane localization of Protein 2B is caused by the specific structure of this protein. 2B consists of two hydrophobic $\alpha$-helices connected with a short linker sequence. (Fig. 3) The first $\alpha$-helix is an amphipathic $\alpha$-helix and reaches from aa37-54. The second $\alpha$-helix is a complete hydrophobic region reaching from aa63-80 [9]. The $\alpha$ helices enable the $2 \mathrm{~B}$ protein to integrate into the membrane of cell organelles like the Golgi apparatus and the ER and disrupt the membrane integrity. Already in 1995, van Kuppeveld investigated the 2B protein of CVB3, especially the C-terminal hydrophobic region. In this study, van Kuppeveld generated several single or double mutants of the $2 \mathrm{~B}$ protein, causing altered hydrophobicity of the protein, but these mutated proteins still allowed the production of viable CVB3 virus particles associated with similar hydrophobicity. When a double mutation was inserted into the 2B protein, as it was done for the four mutants $577 \mathrm{M} / \mathrm{C} 75 \mathrm{M}$ / I64S/V66S, the hydrophobicity of the $2 \mathrm{~B}$ protein was changed more significantly compared to the single mutations and led to the production of nonviable virus particles. All over, the 2B mutations had no effect on the production and processing of the viral polyprotein. They rather had a negative effect on the viral RNA synthesis. This effect is probably based on incorrect membrane insertion of $2 \mathrm{~B}$ followed by a disrupted vesicle formation required for viral replication [18]. Later, van Kuppeveld extended their study and showed that mutants 


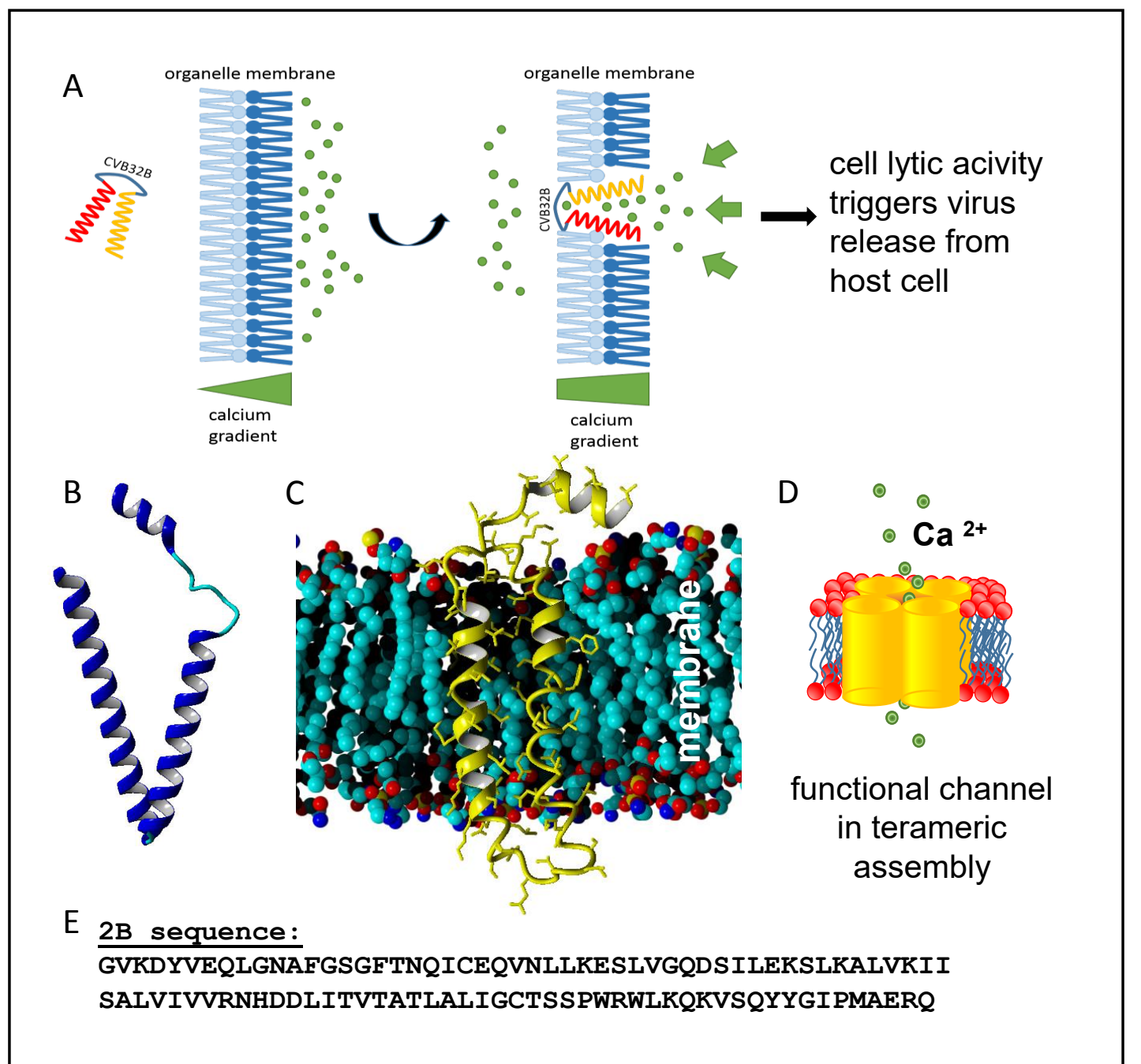

Fig. 3. Viroporin 2B is membrane associated and leads to autophagy and changed calcium homeostasis. A: Viroporin 2B (CVB32B) inserts into cellular membranes of the host-cell and destabilizes the membrane integrity. This leads to uncontrolled release of calcium and other ions from cell organelles. B: 3D Model of Viroporin 2B. C: Model of membrane insertion of 2B. Shown is exemplary the insertion of a $2 \mathrm{~B}$ single protein. D: Membrane insertion of $2 \mathrm{~B}$ under realistic conditions. $2 \mathrm{~B}$ forms tetramers in the host-cell membrane to maximize membrane destabilization and to enhance uncontrolled ion flow into the cytoplasm.

with changed amphipathicity or less cationic residues in the hydrophilic part of the $\alpha$-helix caused the production of non-viable virus particles. This finding suggests that not only the hydrophobicity, but also the charge of the 2B Protein is necessary for the production of viable virus particles [18]. In 1997 van Kuppeveld observed the effect of 2B on the ER of HeLa cells. The cells were either transfected with a cDNA Plasmid pCVB3/T7, containing the whole CVB3 genome, or with the single 2B protein alone. Cells transfected with pCVB3/ T7 showed the typical viroid formation together with the expected reactions of the host cell, as vesicle formation, loss of membrane integrity and changes of intracellular calcium levels. Transfection with the $2 \mathrm{~B}$ protein alone was sufficient to induce vesicle formation and a change in calcium levels. Immunostaining proved that cells expressing $2 \mathrm{~B}$ protein also showed elevated cytoplasmatic calcium concentrations. So it was proven that protein 2B alone induces changes in calcium homeostasis. Due to 2B's ability to integrate into membranes and the fact that calcium is elevated in infected host cells it is reasonable to suspect, that changes in ER function and the loss of its membrane integrity may be the main 
effect of 2B. To prove this point van Kuppeveld performed experiments on cells treated with thapsigargin, which is a strong inhibitor of the ER calcium ATPase (SERCA) [20]. Cells infected with CVB3 or with 2B alone showed a decrease in ER calcium levels in comparison to MOCK (control) transfected cells proving the point that $2 \mathrm{~B}$ is targeting the ER to disrupt the cells calcium homeostasis. The increased cytosolic Ca2+ aids viral release out of the host cell [21]. Thus it was shown that $2 \mathrm{~B}$ and elevated extracellular calcium levels increase the release of viral particles and support the dispersion of CVB3 in the host tissue. As a second target of 2B the Golgi apparatus was identified by de Jong (2003). By using fluorescence labeled $2 \mathrm{~B}$ protein and the generation of several $2 \mathrm{~B}$ mutants containing different motifs of the hydrophobic region 1 (HR1) and hydrophobic region 2 (HR2) of $2 \mathrm{~B}$ it was found that both regions together are responsible for membrane association and correct biological activity, as well as for efficient Golgi targeting. By inserting itself within Golgi membranes under formation of a CVB3-2B tetramer, the membrane of the Golgi gets destabilized. This causes another efflux of calcium out of the Golgi apparatus into the cytoplasm and somehow induces the production of vesicles from the Golgi membrane. In many infected cells the Golgi apparatus is almost used up by the virus for vesicle formation which are abused as membrane associated replication complexes for the virus [22].

The origin of the vesicles formed by $2 \mathrm{~B}$ is autophagosomal as the study of $\mathrm{Wu}$ et al. (2016) indicates. This research team found that the expression of $2 \mathrm{~B}$ alone is producing vesicles in HeLa cells bearing the autophagosomal marker LCIII, revealing that $2 \mathrm{~B}$ is manipulating the autophagy of the cell to produce replication complexes for virus production [9]. Using a mutant library of $2 \mathrm{~B}$, the necessary motif for vesicle formation was identified. The conclusion was that parts of HR1 and HR2 are necessary for autophagosome formation, at least 2B aa106-249, but that the complete hydrophobic regions are required for efficient autophagy. Furthermore by directed mutagenesis, an amino acid was identified, which is crucial for the autophagosomal activity of 2B. The V56 which is located in the hydrophilic linker between the two hydrophobic regions seems to be important for the formation of 2B's hairpin structure and so its ability to insert itself into the membranes of the ER or the Golgi. All generated mutants with amino acid changes in the hairpin loop were able to produce autophagosomes, except for V56A, where valine was changed to alanine, which lacked the ability to form autophagosomes [9]. So the amino acid composition of the linker is important for the correct structure and function of $2 \mathrm{~B}$, so that it can fulfill its role in the viral life-cycle. The activity of $2 \mathrm{~B}$ in the host cell surely does not stay unrecognized and subsequently the cell reacts stressed. Just recently the group of Zhang et al. found the connection between endoplasmatic reticulum stress and progressing viral myocarditis. In an extensive mouse study it could be shown that the reduction of endoplasmatic reticulum stress by tauroursodeoxycholic acid (TUDCA) [23-25]. In conclusion endoplasmatic reticulum stress may be one of the major reasons for cell death and following fibrosis in CVB3 infected cardiac tissue. The endoplasmatic reticulum stress and the cell death leads to the production of pro-inflammatory cytokines like IL-6, IL-12, MCP-1 and IP-10 and to the migration of responding macrophages into infected tissues. The macrophages significantly elevate inflammation leading to an increased myocarditis by secreting TNF- $\alpha$ and IL-6 [26]. The endoplasmatic reticulum stress inhibitor TUDCA lowers the levels of the secreted stress Cytokines IL-6, IL-12, MCP-1 and IP-10 significantly and reduces the amount of migrated macrophages, which could become relevant in CVB3 therapy [27].

\section{Proteases $2 \mathrm{~A}$ and $3 \mathrm{C}$ play important roles in viral life cycle and host cell manipulation}

The proteases $2 \mathrm{~A}$ and $3 \mathrm{C}$ increase expression of Bax and p53 and decrease the level of Bcl-2, destabilizing cellular homeostasis and leading to cell death.

The most studied and assumed most responsible proteins for pathologic effects in viral myocarditis are viral proteases. Viral proteases are enzymes encoded by the viral genome which are responsible for the cleavage of the viral polyprotein into functional single proteins, 


\section{Cellular Physiology Cell Physiol Biochem 2019;53:121-140 \\ \begin{tabular}{ll|l} 
and Biochemisty $10.33594 / 000000125$ & C 2019 The Author(s). Published by \\
Published online: 24 June 2019 & Cell Physiol Biochem Press GmbH\&Co. KG
\end{tabular}}

as well as for the cleavage of host cell proteins for various purposes. These purposes can be the shutdown of host cell translation, destabilization of cellular organelles, disturbance of physiological functions and more. Coxsackievirus B3 is coding for 2 proteases within its $7.4 \mathrm{~kb}$ long genome. These proteases are known as proteins $2 \mathrm{~A}$ and $3 \mathrm{C}$ and are key players of the viral life-cycle. In the case of CVB3, especially the protein $2 \mathrm{~A}$ protease was extensively studied.

The CVB3 proteases are known to have many effects on the host cell, including proteolysis and mitochondrial degradation. The most striking effect by $2 \mathrm{~A}$ is the production of stress granules (SG) by the infected cell [28]. Stress granules are seen as granular aggregates produced by a cell when it gets exposed to environmental stress like hypoxia, radiation, heat shock or endoplasmatic reticulum stress [29]. Various types of viral infections are known to induce the production of stress granules such as respiratory syncytical virus, mammalian orthoreo viruses, hepatitis C virus and Coxsackievirus B3. SG's induced by environmental stress contain a variety of cellular components e.g. silent mRNA, eukaryotic translation factors as elF4E, elF4G, elF4A, elF4B, elF3, elF2, RNA binding proteins, PABP1, ELAV, Hu protein HUR, polysomal ribonuclease 1 PMR-1, TTP, T-cell-restricted intracellular antigen 1 TIA1, TIA- 1-related protein TIAR, FMRP and Ras-Gap SH3-binding protein G3BP1. These components can act as markers for stress granules. Commonly used as markers in research are HuR, TIA1, and G3BP1 [30]. Stress granules induced by viruses like CVB3 differ in the containment of factors from SG's induced by environmental stress. Viral SG's, and especially picornavirus SG's, contain several components not colocating with normal SG's like Sam68 and SRp20, factors known to be involved in mRNA binding, and splicing [31,32]. The formation of stress granules is linked closely to the phosphorylation of eukaryotic translation initiation factor 2a (elF2a). If elF2a gets phosphorylated, less elF2-GTP-tRNAiMet, a ternary complex which joins with tRNAmet at the $43 \mathrm{~S}$ preinitiation complex, is available. This results in a decreased mRNA translation and therewith leads to an untranslated mRNA overshoot in the cell. The futile mRNA is transported into plasmic foci, the so called stress granules. The mRNA transport to the SG's is mediated by the proteins TIA-1 and TIAR [33]. An infection with Coxsackievirus B3 and other members of the Enterovirus genus leads to the production of stress granules as well. In a study from 2014 by Wu et al. the process of SG formation in enterovirus infections was observed. They showed that the SG marker T1A1 localized in granules induced after CVB3 infection of HeLa cells, showing that CVB3 is a potent agent for SG formation. To identify which of CVB3's proteins affect the generation of SG's, HeLa and Vero cells were co-transfected with pm-Cherry-Hur and a respective plasmid coding for EGFPtagged CVB3 protein VP1; VP4-3; 2A; 2B; 2C; 3A; 3B; 3C and 3D. Only in cells transfected with CVB3-2A, mCherry-HuR was translocated from the nucleus to the cytoplasm and accumulated in granular structures [34]. In mutant 2A G122E almost no SG's occurred. The western blot in which lysates of the transfected HeLa cells were analyzed indicated, that only the mutant 2A G122E showed reduced proteolytic activity concerning elF4G cleavage. Thus it was proven that SG formation is due to CVB3 2A alone [30]. If this stress granule formation is a direct result of $2 \mathrm{~A}^{\prime}$ s proteolytic activity or if it is a secondary effect of the host cell reacting on 2A-cleavage of proteins was still unclear. A recent study suggests an antiviral effect of stress granules in early stages of viral infection. Zhai et al. showed that CVB3 infection does not alter the effect of NaAs (Sodium Arsenite) alone [35, 36]. NaAs is a potent agent for stress granule formation in human cells. Western blot analysis showed that the amount of phosphorylated elF2A is significantly elevated in cells treated with NaAs before CVB3 infection, whereas the production of viral proteins showed the exact opposite picture. It seems as if the formation of SG's in early stage of viral infection lowers the amount of viral proteins, and therewith slows the viral life-cycle [36]. Thus, SG formation may be a host cell reaction to limit viral infection and increase the chance of survival. 


\section{A and DAP5}

Protease 2A cleaves the host cell proteins eIf4G and DAP5 leading to changes in translation and cell death, whereas protease $3 \mathrm{C}$ cleaves procaspase 8 and induces mitochondrial apoptosis pathway. As mentioned before CVB3 protein 2A fulfills several distinct tasks within the host cell. As protease it is responsible for cleavage of several host cell proteins. These cleavage targets include translation initiation factors like elf4G and DAP5 which are responsible for the cap-dependent and IRES-dependent translation of host-cell proteins. Elf4G and DAP5 are homologues of which elF4G is responsible for the cap-dependent translation and DAP5 for the IRES-dependent translation in cells. DAP5 is mainly active in early development, in cell cycle regulation and under ER-stress conditions and enhances the expression of stress proteins like Bcl-2, p53, XIAP, CDK1, c-Myc and others [37]. For this reason DAP5 and elf4G may represent interesting targets for investigation in ER-Stress of CVB3 infection. Viral proteases are responsible for the cleavage of DAP5 and elF4G and so lead to changes in translation and cell death $[7,38]$. However, the exact mechanism of translation factor cleavage was poorly explored until Hanson et al. showed that endogenous DAP5 was cleaved after 48 hours post infection (hpi) only by protease $2 \mathrm{~A}$ but not by $3 \mathrm{C}$. The factor elF $4 \mathrm{G}$ was cleaved by $2 \mathrm{~A}$ even faster, after $24 \mathrm{hpi}$, compared to DAP5 indicating that elf4g is the main agent for cleavage in early phase of CVB3 infection, but that DAP5 gets important in the later stages of infection. The DAP5 cleavage site was localized at glycine 434. After cleavage of DAP5 by CVB3 2A the resulting DAP5-N terminus was accumulated in the nucleus, probably modifying protein synthesis of the host-cell. Samples transfected with DAP5-N showed a 2.5-fold higher translation of VP1 capsid protein compared to samples transfected with DAP5-C. So it was proven that the cleavage product DAP5-N supports replication of CVB3 in the host- cell nucleus. Knock-down of wtDAP5 reduced the amount of produced viral particles in infected HeLa cells by $80 \%$ which proves the central importance of DAP5 in the viral replication process [39]. Overexpression of DAP5-N and wtDAP5 showed increased expression of p53 and Bcl-2 whereas DAP5- C led to increase in p53 and decrease in Bcl-2. The emerging imbalance generated by an overshoot of p53 and a lack in Bcl-2 surely induces the apoptosis of infected cells and supports the release of viral progeny, and less Bcl-2 means a weakened viability of cells, respectively [23] (Fig. 4).

Negative effects on cell viability under the influence of proteases $2 \mathrm{~A}$ and $3 \mathrm{C}$ was also shown in a study by Chau et al. in 2007 [7]. Plasmids encoding proteases 2A and 3C, pCIneo2A and pCI-neo3C, were generated and transfected into HeLa cells. Cells transfected with pCI-neo2A showed cell detachment and shrinkage after $24 \mathrm{~h}$ after transfection. The same phenotype was seen after transfection with pCI- neo3C after $48 \mathrm{~h}$, therefore $24 \mathrm{~h}$ slower than for pCI-neo2A. Additionally, a cleavage of procaspase 3 was verified in both conditions, indicating the activation of the caspase 3 dependent apoptosis in transfected cells. After 96 hours almost all cells detached and underwent apoptosis. Caspase 3 activation was further verified by proving the cleavage of PARP, a target protein of caspase 3 , which is associated with DNA repair [7]. Caspase 3 can either be activated by proteolytic function of enzymes like $2 \mathrm{~A}$ and $3 \mathrm{C}$, or by mitochondria-mediated cell death pathway $[7,8]$. Transfections of either protease $2 \mathrm{~A}$ or protease $3 \mathrm{C}$ caused elevated cytochrome c (CYT c) release, indicating that the mitochondrial cell death pathway is involved in CVB3 infection. The role of each protease was further investigated. Cells transfected with protease $3 \mathrm{C}$ showed an increased amount of cleaved procaspase 8 whereas cells transfected with $2 \mathrm{~A}$ did show just a slight increase in cleaved procaspase 8 in the early phase after transfection. Procaspase 8 induces direct mitochondrial injury which explains the increased cytochrome c concentration in cells under influence of $3 \mathrm{C}$ and maybe $2 \mathrm{~A}$. An important key player for mitochondrial injury and following apoptosis is the protein Bax and its counterpart Bcl-2. Bax leads to direct cytochrome c release out of the mitochondria, while Bcl-2 shows strong anti-apoptotic function. So the influence of $2 \mathrm{~A}$ and $3 \mathrm{C}$ on these mediators was investigated. While expression of Bcl-2 was not changed, the expression of Bax increased significantly in 3C transfected cells. In comparison, cells transfected with $2 \mathrm{~A}$ showed just a mildly increased level of 
A

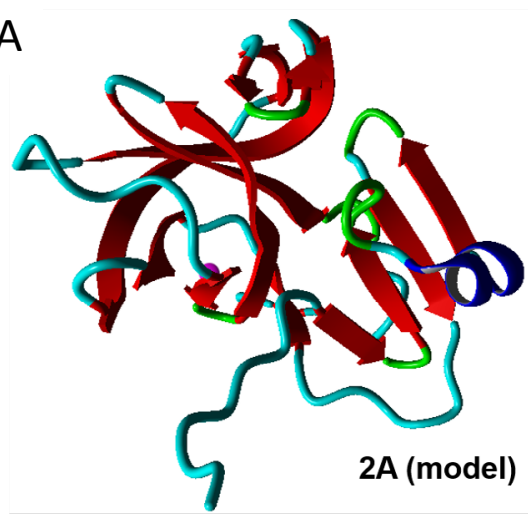

2A sequence:

GAFGOOSGAVYVGNYRVVNRHLATSADWONCVWESYN RDLLVSTTTAHGCDIIARCQCTTGVYFCASKNKHYPI SFEGPGLVEVQESEYYPRRYQSHVLLAAGFSEPGDCG GILRCEHGVIGIVTMGGEGVVGFADIRDLLWLEDDAM EQ
B

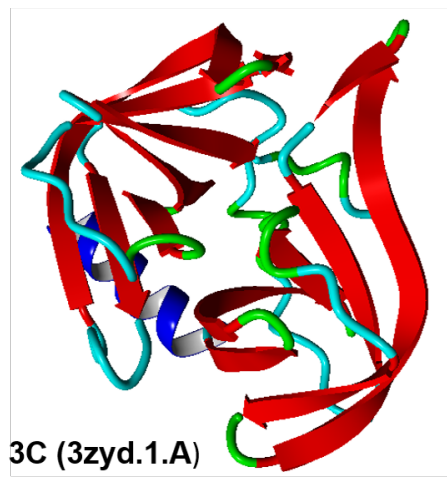

$3 C$ sequence:

GPAFEFAVAMMKRNSSTVKTEYGEFTMLGIYDRWAVL PRHAKPGPTILMNDQEVGVLDAKELVDKDGTNLELTL LKLNRNEKFRDIRGFLAKEEVEVNEAVLAINTSKFPN MYIPVGQVTEYGFLNLGGTPTKRMLMYNFPTRAGQCG GVLMSTGKVLGIHVGGNGHQGFAALLKHYFNDE

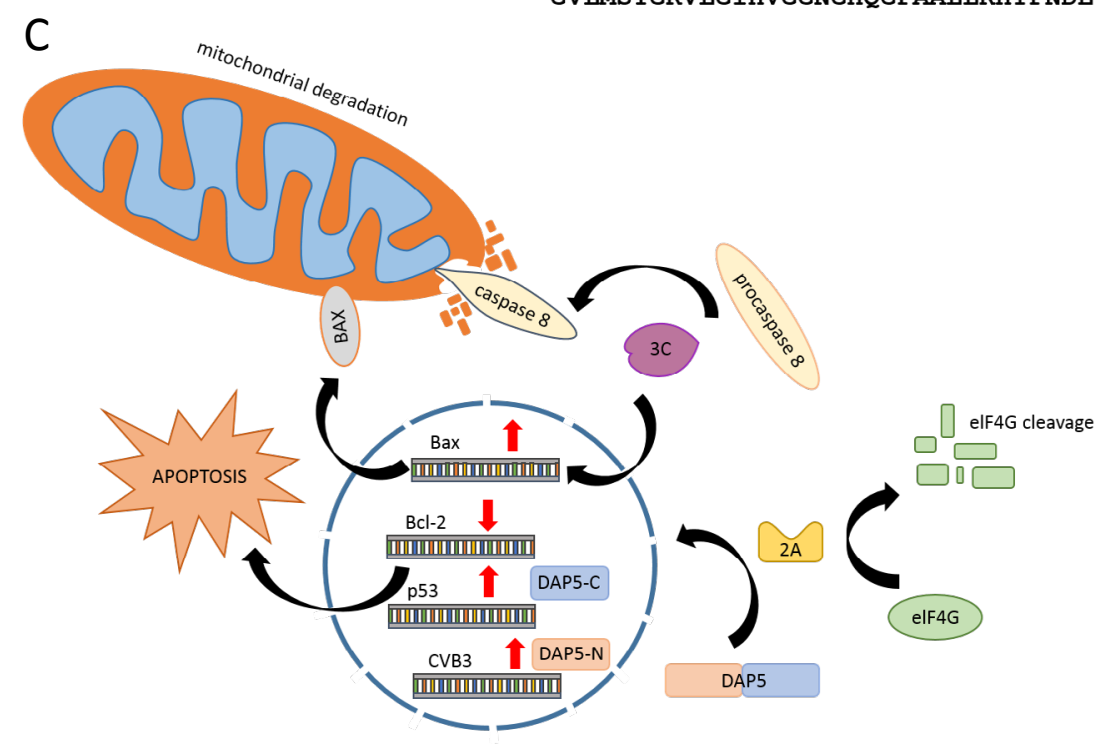

Fig. 4. A: 3D Model of CVB3 Protease 2A. B: 3D Model of CVB3 Protease 3C. C: Function of proteases 2A and $3 \mathrm{C}$ in the host-cell. Protease $2 \mathrm{~A}$ is responsible for the cleavage of elF4G and so suppresses host-cell translation. Cleavage of DAP5 by CVB3 2A leads to the byproducts DAP5-N and DAP5-C, which suppress the transcription of anti-apoptotic genes and support the transcription of pro-apoptotic genes. Protease 3C cleaves and activates procaspase 8. Furthermore it supports the expression of Bax. Both effects lead to mitochondrial degradation and cell-death.

Bax 72 hours post transfection. The resulting imbalance of Bax and Bcl-2 may contribute to apoptotic function of protease 2A and $3 \mathrm{C}$ of CVB3.

\section{CVB3 and its interactions with mitochondria}

In a murine model it was shown, that CVB3 impacts mitochondrial respiratory chain and the energy metabolism of cardiomyocytes. An additional imbalance of Drp1 and Fis1 leads to increased mitochondrial fission and cell death. 
The mitochondrial respiratory chain, which is carried out by the complexes I-V located in the inner mitochondrial membrane, is the main mechanism for cellular energy carrier production. Its ability to produce cellular ATP via glycolysis and $\beta$-oxidation of lipids provides large amounts of energy equivalents to allow for cellular homeostasis and performance.

Electron donors, as NADH or FADH2, are oxidized in the mitochondrial complexes I and II, providing electrons and protons for the generation of ATP via the respiratory chain. At complex I, NADH gets oxidized to NAD $++\mathrm{H}+$ and e-. Protons get pumped out of the inner mitochondrial space by complex I into the cytoplasm. Electrons derived from the cleavage of $\mathrm{NADH}$ are transferred to ubiquinone, which acts as a proton acceptor and gets reduced to ubiquinole. Alternatively, electrons are also delivered by complex II by oxidizing succinate to furamate using FADH2 as oxidant. Each involved succinate provides two electrons to the electron transport chain. The released protons of FADH2 get transported out of the mitochondrial matrix by complex III. Subsequently, ubiquinole delivers its bound electrons via complex III to cytochrome c. An iron atom in cytochrome c gets reduced from Fe3+ to $\mathrm{Fe} 2+$ and carries electrons to complex IV. The electrons are used to generate water molecules from $\mathrm{O} 2$ and remaining $\mathrm{H}+$. An $\mathrm{H}+$ surplus can also be compensated by complex IV pumping the protons out into the cytoplasm [40]. The increased protonation of the cytoplasm in proximity to the mitochondrial membrane is subsequently used by complex $\mathrm{V}$, the ATP-synthase, to generate ATP. Protons located in the cytoplasm are transported through the ATP-synthase into the mitochondrial matrix. This proton flow drives the continuous $360^{\circ}$ rotation of the F0 subunit, the membrane associated subunit of the ATP-synthase. This rotation is permanently opening and closing catalytic sites in the ATP-synthase F1 subunit where ADP and Pi can bind. So ATP is generated, enabling correct cell function (Fig. 5) [41]. Viruses, including CVB3, are known to interact with the mitochondrial respiratory chain in various ways. As mentioned before, proteases $2 \mathrm{~A}$ and $3 \mathrm{C}$ induce mitochondrial dependent apoptosis and actively induce cell death. But host cells have the ability to counteract CVB3 infection using its mitochondria. In a study by Ebermann et al., two mouse lines were used to investigate the replication of CVB3 by subsequently monitoring the mitochondrial activity. The first mouse line used was C57BL/6, a mouse line known to be resistant to chronic CVB3 infections. The second mouse line was A.SW/SnJ, which easily develops chronical outcomes of CVB3 when infected. The differences in mitochondrial activities and viral titers were assessed. The activity of the first four complexes of the mitochondrial respiratory chain (RC) was measured after the isolation of mitochondria from hearts of CVB3 infected C57BL/6 and A.SW/SnJ mice. The measurement was done spectrometrically by measuring the usage of the specific substrate of each RC complex over time. CVB3 infected A.SW/SnJ mice showed restricted activity of the measured RC complexes I-IV by an average of $16 \%$. The infected C57BL/6 mice, which show a functional immune response to CVB3 show a more complex mitochondrial reaction. The activity of complex II was restricted by $12.9 \%$ whereas the activity of complex I and III was elevated by $21.7 \%$ and $44.0 \%$. The activity of complex IV stayed almost unchanged. These findings correlate with results of mass spectrometry analyses of the whole cell proteome of infected mice of both lines. In this experiments, the proteome of C57BL/ 6 and A.SW/SnJ cardiac tissue was compared to each other. The results showed that SDHC (succinate dehydrogenase unit C), a core unit of complex II, was downregulated in C57BL/6, which could explain the decreased activity of complex II in the complex activity measurements. For complex I several proteins were upregulated including NDUFA1, NDUFA2, NDUFS4, which are known to have significant impact on the complex I activity. Upregulation of these and other parts of complex I can explain the increase of complex I activity measured in the experiment. Downregulation of complex III proteins was observed (3/11 proteins were decreased) upon CVB3 expression in C57BL/6 mice. One of the downregulated complex III proteins was the core unit UQCR10 which directly interacts with cytochrome $\mathrm{c} 1$ and which is a key player in the electron transport. Downregulation of UQCR10 should lead to a decreased activity of complex III, which is in contrast to the observed activity of complex III in CVB3 infected cells of C57BL/6 mice. A compensatory effect against the virus-induced change in protein expression may thus 


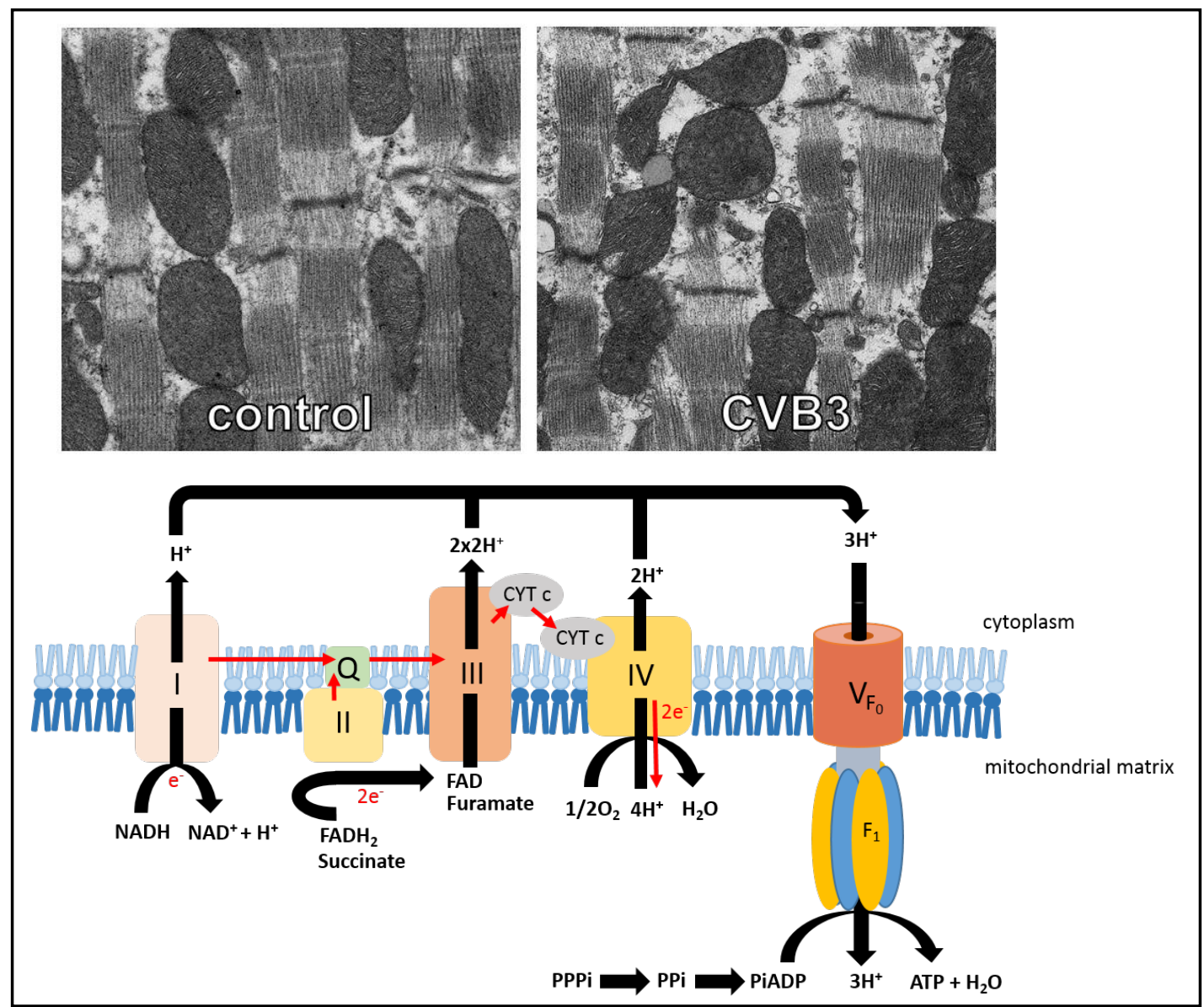

Fig. 5. Effect of CVB3 on mitochondria. Expression of CVB3 genome in murine cardiac tissue results in tissue damage. Besides damage in contractile tissue the mitochondria tend to retain a rounded phenotype (upper picture, EM graph at 10.300x magnification). Besides structural effects on the mitochondria, the mitochondrial respiratory chain is affected by CVB3 (lower panel). The first four complexes of the respiratory chain (I-IV) build up a proton gradient in the across the inner mitochondrial membrane and transport free electrons over ubiquinone and cytochrome c along the membrane. Complex V, the ATP-Synthase, uses the proton gradient to generate ATP by shuttling protons back into the mitochondrial matrix.

be present. Only two out of 13 complex IV proteins were downregulated (COX7A2L and COX7A1) [42], which did not result in changed complex IV activity of CVB3 infected C57BL/6 mice. The elevated activities of complex I and complex III may be very important for the pathology of CVB3 infections. Elevated activity of complex I and complex III are reported to enhance oxidative stress in affected cells by generation of ROS within the mitochondria [43]. Indeed, the upregulation of SOD2 and downregulation of cytosolic catalase in C57BL/6 was detected and support the accumulation of ROS in affected tissue and induce oxidative stress, subsequently leading to tissue damage due to mitochondrial apoptosis. Elevated levels of the oxidative stress marker LPO in C57BL/ 6 tissue verified increased oxidative stress levels in infected cells [44]. The resultant mitochondrial apoptosis was associated with increased expression of Bax, Bcl-2 and caspase 3 in cardiac tissue of C57BL/6 mice, indicating strongly activated mitochondrial apoptosis as defense mechanism of infected cells against CVB3. TUNEL stains of C57BL/6 mouse tissue showed apoptotic cells within the tissue while tissue of A.SW/SnJ mice stayed unaffected. All these findings support the hypothesis that the mitochondrial RC in cardiomyocytes is changed in acute CVB3 infections, not only due to viral effects but also as a defense mechanism of the host cell against viral replication. 


\section{Cellular Physiology Cell Physiol Biochem 2019;53:121-140 \\ \begin{tabular}{ll|l} 
and Biochemisty $10.33594 / 000000125$ & C 2019 The Author(s). Published by \\
Published online: 24 June 2019 & Cell Physiol Biochem Press GmbH\&Co. KG
\end{tabular}}

The chronic outcome of CVB3 infections is still quite unclear. Chronic effects could only be observed in A.SW/SnJ mice because all infected C57BL/6 mice recovered from CVB3 without a chronical outcome due to a sufficient immune response. A.SW/SnJ mice were tested for pathologic effects of CVB3 after 90 days of infection. After this extended period, the activity of complex I was still restricted to around $80 \%$ of normal activity, while the activity of all the other complexes returned to normal levels. A plaque forming assay showed no further propagation of CVB3, but an immune response was detectable, indicated by still elevated levels of Bax $(+133,1 \%)$ and Bcl-2 $(+145.1 \%)$. Other proteins indicating oxidative stress or mitochondrial apoptosis were not changed in expression anymore [42]. Thus, the chronic murine model of CVB3 infection leaves several questions unsolved. A transcriptomics study of Xu et. al. 2011 shows that CVB3 markedly changes the host cell metabolism and especially in the respiratory chain of infected mice [45]. Infected Balb/c mice hearts were observed 104 days after CVB3 infection for ongoing immunological and viral effects. Despite the increased heart volume as result of ongoing fibrosis, the hearts contained significantly higher levels of collagen and showed a strongly reduced cardiac output. The transcriptome of CVB3 infected hearts with chronic outcome showed widely decreased transcription of genes encoding mitochondrial proteins, especially of proteins belonging to complex I and complex IV of the RC [45]. While no functional data were generated in this study, the transcriptomics show that CVB3 is changing the metabolism of a host cell in the chronic outcome over a long period of time as well. This leads to severe pathological effects like cardiac cell death and cardiomyopathy due to cell starvation or dysregulatory effects which are commonly observed [46].

The influence of CVB3 on mitochondria may not be regarded solely as negative, but could point to a possible target for a CVB3 therapy. As discussed before, a functional immune response, as well as a shift in the RC of the host cell to fight the viral infection of CVB3, seems to be crucial for sufficient recovery. If there was a possibility to allow the cell to fulfill these tasks without transit towards mitochondrial apoptosis, leading to cell death and fibrosis in the heart tissue, patients may be able to fight CVB3 and other enterovirus infections without permanent late-effects [47]. A suitable target for this kind of therapy seems to be the dynamin related protein 1 (Drp1) [48]. A study by Lin et. Al. from 2017 observed the interaction of Drp1 and its antagonist the mitochondrial fission protein 1 (Fis1). It was already known that the equilibrium Drp1 and Fis1 is responsible for correct mitochondrial fission and fusion processes. An imbalance between these two proteins leads to increased mitochondrial fission or uncontrolled fusion, changing the efficiency of the mitochondrial RC [49]. In a normal state, Drp1 is localized in the cytoplasm and gets recruited to the mitochondria by conformational changes in the GTPase cycle. The resulting delocalization of Drp1 leads to mitochondrial fragmentation. In CVB3 infected mouse hearts Drp1 is relocated from the cytoplasm to the mitochondria inducing mitochondrial fragmentation. Furthermore, the basal expression of Drp1 increased by 3.2-fold resulting in an even stronger effect on the mitochondria. The associated Fis1 is upregulated by 1.5 -fold and the GTPase Mfn1 is downregulated by 0.7 -fold reducing the ability of the cell to fuse mitochondria in the correct way. Knowing that, Drp1 seems to have major impact in mitochondrion destruction in CVB3 infection. A selective inhibition of Drp1 might be a sufficient approach to stop further pathologic effects. In line with this hypothesis the selective Drp1 inhibitor mdivi-1 was used on CVB3 infected mice for 14 days. Mice treated with mdivi-1 recovered from their weight losses, which were caused by the viral infection. TUNEL staining showed a decrease in apoptotic cells under mdivi-1 treatment which was around 2 -fold higher in the untreated group. Serum levels of cTNI and CK-MB, which are indicators for cardiac cell death, decreased significantly in mdivi-1 treated mice, and the activities of COX (Cytochrome c oxidase) and SDH (Succinate dehydrogenase) in the mitochondria were higher than in mdivi-1 untreated mice [48]. Although the activities of COX and SDH did not reach the level of healthy, CVB3 uninfected cells. But even if the treatment with mdivi-1 is not inhibiting all viral effects, it improved the viability of the treated mice and eased the pathological effects of CVB3, giving hope for a sufficient treatment in the close future. 


\section{Cellular Physiology Cell Physiol Biochem 2019;53:121-140 \\ \begin{tabular}{ll|l} 
and Biochemisty $10.33594 / 000000125$ & C 2019 The Author(s). Published by \\
Published online: 24 June 2019 & Cell Physiol Biochem Press GmbH\&Co. KG
\end{tabular} \\ Peischard et al.: CVB3 Host Cell Interaction}

\section{The impact of CVB3 on cardiac ion channels and contractility}

CVB3 infection increases SGK1 expression, which in turn promotes insertion of KCNQ1channels into the cellular membrane. This phenotype could result in arrhythmias and sudden cardiac death.

Cases of sudden cardiac death due to viral myocarditis are regularly observed and diagnosed in thousands of cases every year [50]. The exact mechanisms underlying these spontaneous, unforeseen events is still unclear up to this point, but are in focus of current research. Contraction of the heart is a complex and synchronized event, in which every component in cardiac conduction has to work correctly. Changes in cellular structure, cellto-cell connection, homeostasis and membrane protein expression are just some possible explanations for sudden cardiac death in viral myocarditis. As discussed before, CVB3 is known to induce changes in the homeostasis and energy balance of cells. It also induces cellular stress and disrupts the calcium homeostasis. The effect of CVB3 on the expression and localization of membrane proteins is still incompletely understood. The fact that sudden cardiac death is a spontaneous event, changes in ion channel expression and distribution may serve as an explanation. In 2013, cardiac ion channels were put into focus of a scientific observation concerning CVB3 myocarditis for the first time.

The expression of ion channels responsible for the regular heartbeat, by generating the cardiac action potential in mice and men, was monitored by Steinke et al. in 2013. The cardiac action potential in ventricular myocytes, which are the cells most influenced by CVB3, is characterized by the currents INa, Ito, ICaL, IKr, IKs, and IK1, generated by several ion channels [51]. A study from 2011 suggested that CVB3 may be the cause of channelopathies in infected cardiac tissue, especially influencing the channels KCNQ1/KCNE1, hERG1 and Cav1.2 [52].. The voltage-gated potassium channel KCNQ1, mainly expressed in ventricular cardiac tissue, is the mediator of the delayed, slow rectifying $\mathrm{K}+$ current and is crucial for repolarization of cardiac myocytes. KCNQ1 is terminating the cardiac action potential and thus responsible for correct cardiac conduction and contraction of myocytes. Coexpression with KCNE1, a regulatory subunit of KCNQ1, is modulating its activation and is normally increasing the current of KCNQ1. HERG1 or Kv11.1 is the $\alpha$-subunit of the hERG channel (human Ether-à-go-go- Related Gene). This channel takes also part in the repolarization of myocytes in the heart and forms the rapid delayed rectifier current (IKr). The third ion channel modulated by CVB3 is Cav1.2, the $\alpha-1 \mathrm{C}$ subunit of the L-type calcium channel. The complete channel consists of the $\alpha-1, \alpha-2$ and $\beta$ ? 1:1:1 and is responsible for the L-type Ca2+ currents. These currents control the release of calcium from the ER or SR (sarcoplasmic reticulum) into the cytoplasm via ryanodine receptor 2 . The L-type calcium current and the following release of calcium out of the SR mediate the cardiac contraction. The channels were studied in Xenopus laevis oocytes. The currents of KCNQ1/KCNE1 were elevated to around 125.5\% in contrary to the currents of hERG1 and CAV1.2, which showed a decrease by around 59.1\% and 83.4\%. In comparison, other measured channels like Kv4.3, Kir 21-3 and Nav1.5 showed no significant changes in current generation, indicating that the effect of CVB3 seems to be specific to several cardiac channels. To verify this finding, GFP-tagged clones of the channels were injected into Xenopus laevis oocytes and analyzed for their localization. KCNQ1/KCNE1 showed an increased membrane abundance under the influence of CVB3. For hERG1 and Cav1.2, the fluorescence images showed a decreased membrane localization under CVB3 influence supporting the findings of the voltage clamp measurements [51].

Especially KCNQ1/KCNE1 plays an important role in the regulation of the cardiac action potential in stress situations and therefore is an interesting candidate in cases of sudden cardiac death associated with CVB3, which are triggered by stress conditions [53]. In a preliminary study of Seebohm et al. in 2008 it was shown that SGK1, the Serine/threonineprotein kinase-1, is responsible for the increase of the KCNQ1/KCNE1 membrane expression [54]. It was observed that CVB3 increases the expression of SGK1 in Xenopus laevis oocytes 1 day and 2 days and in mouse hearts 12 hours after injection. The upregulation of the 


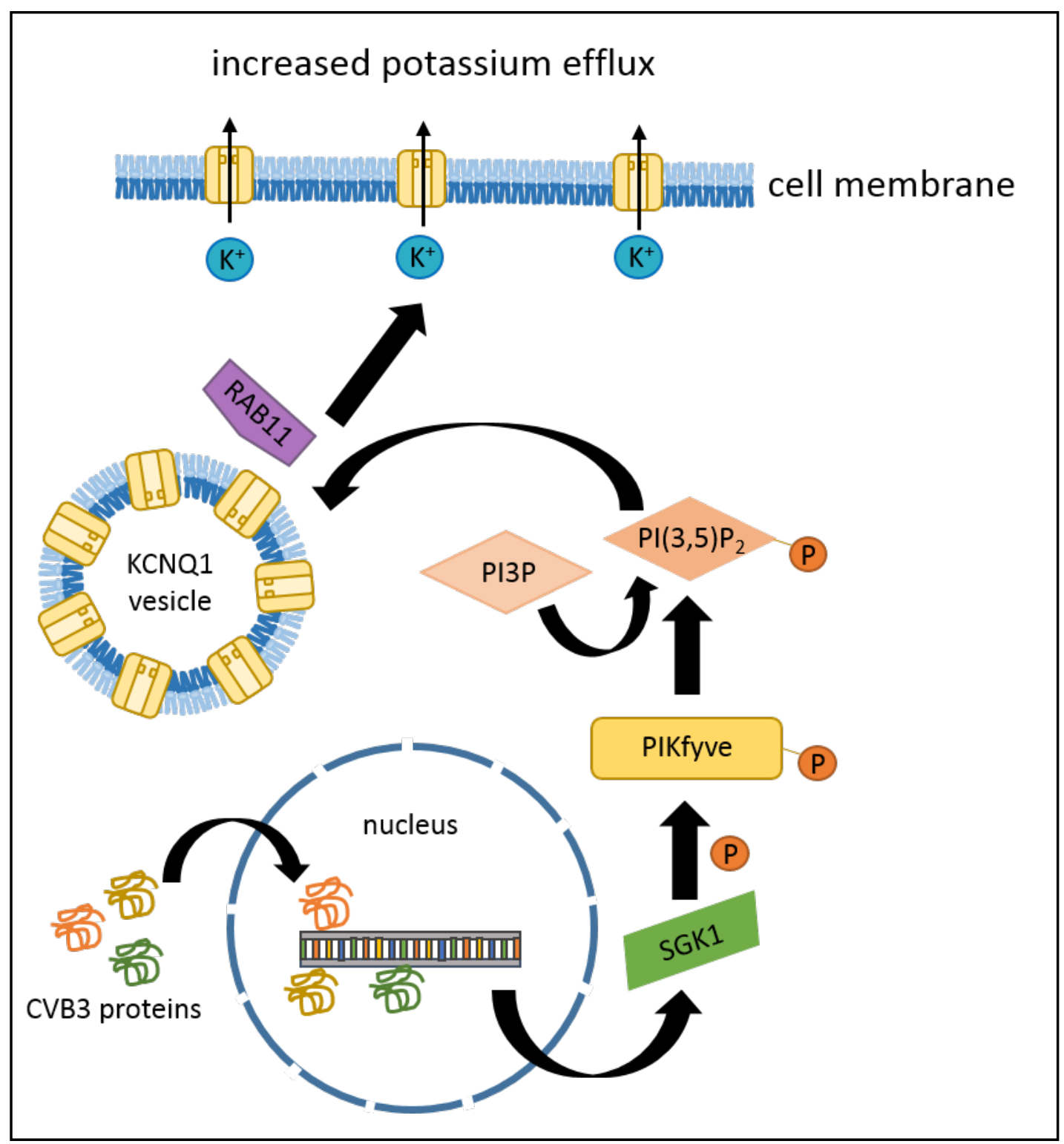

Fig. 6. Influence of CVB3 on vesicle transport and on ion-channel membrane integration in the case of KCNQ1. CVB3 elevates the expression of SGK1 leading to increased activation and membrane transport of KCNQ1-containingvesicles. This results in elevated KCNQ1 membrane localization and elevated potassium currents.

SGK1 pathway leading to increased membrane insertion of KCNQ1/KCNE1 explains the findings of the voltage clamp measurements where increased currents were monitored. The effect could be inhibited by a small molecule inhibitor of SGK1. Equal experiments were performed with parovirus B19, which showed no effect on the SGK1 expression and KCNQ1/KCNE1 localization, indicating that the manipulation of SGK1 may be unique to CVB3 or at least to the enterovirus genus. Coexpression of CVB3's single non-structural proteins together with either KCNQ1/KCNE1, hERG1 or Cav1.2 revealed the proteins 2A, $2 \mathrm{BC}, 3 \mathrm{~A}$ and $3 \mathrm{~B}$ as main mediators for changes in ion-channel distribution. The effects of the single CVB3 proteins differ strongly concerning up-and downregulation, making it impossible to pinpoint one single protein as cause for channelopathy [54]. It is to assume that an interaction of several CVB3 proteins leads to the observed channelopathy in full scale CVB3 infections. (Fig. 6) In 1998, Wessely et al. already observed myopathic effects on 


\section{Cellular Physiology Cell Physiol Biochem 2019;53:121-140 \begin{tabular}{ll|l} 
DOl: $10.33594 / 000000125$ & & $\begin{array}{l}\text { O 2019 The Author(s). Published by } \\
\text { Cell Physiol Biochem Press GmbH\&Co. }\end{array}$
\end{tabular} \\ Peischard et al.: CVB3 Host Cell Interaction}

the heart during CVB3 infections in mice. Alongside significant cell shortening, a decreased and disturbed excitation/contraction coupling was monitored, indicating that changes in ion channel distribution also lead to changed physiological effects in cardiomyocytes [55]. Besides a significantly hyperpolarized resting membrane potential, no severe changes in the cardiac action potential were observed. The APD90 value was comparable in wt and in CVB3 infected mouse cardiomyocytes as well as the EAD and the heart rate of Langerhoff perfused hearts. All in all, it seems that the observed channelopathy does not have a striking influence on the cardiac function under resting condition [56]. However, it was not tested if $\beta$-adrenergic stress leads to stimulation of key ion channels ICaL and IKs and if stress conditions generate the arrhythmic substrate for potential lethal arrhythmias. The more it seems, that further mechanisms, like long-during cardiac inflammation and fibrosis due to myocardial apoptosis may be the main reasons for sudden cardiac death. Surely it remains still to investigate if channelopathies may promote cardiac death in stress situations or at least play a partial role under certain conditions. This has to be the task of upcoming studies.

\section{Conclusion}

Summarizing, Coxsackievirus B3 manipulates diverse host cell functions and structures by expression of several multi-functionally active proteins. These CVB3-protein functionalities include proteolytic, transcriptional and translational functions to reprogram host cell behavior like vesicle trafficking, calcium handling and cell survival pathways. Thus, CVB3 seizes the host cell to allow for controlled and efficient virus production enabling virus propagation.

\section{Acknowledgements}

We thank Prof. Dr. Karl-Heinz Klempnauer from the Institute for Biochemistry, Westfälische-Wilhelms- Universität, D-48149 Münster, Germany, for proof reading and for professional advice. This work was supported by grants IMF-SE 111712 and DFG-SE1077-3/3 to GS.

\section{Disclosure Statement}

No conflicts of interest exist.

\section{References}

1 Feuer R, Ruller CM, An N, Tabor-Godwin JM, Rhoades RE, Maciejewski S, Pagarigan RR, Cornell CT, Crocker SJ, Kiosses WB, Pham-Mitchell N, Campbell IL, Whitton JL: Viral persistence and chronic immunopathology in the adult central nervous system following coxsackievirus infection during the neonatal period. J Virol 2009;83:9356-9369.

2 Li XZ, Xia YH, Huang SP, Liu FD, Ying Y, Xu QF, Liu X, Jin GL, Papasian CJ, Chen J, Fu MG, Huang XT: Identification of the interaction of vp1 with gm130 which may implicate in the pathogenesis of cvb3induced acute pancreatitis. Sci Rep 2015;5:13324.

3 Bowles NE, Richardson PJ, Olsen EGJ, Archard LC: Detection of coxsackie-b-virus-specific rna sequences in myocardial biopsy samples from patients with myocarditis and dilated cardiomyopathy. Lancet 1986;1:1120-1124.

4 Flynn CT, Kimura T, Frimpong-Boateng K, Harkins S, Whitton JL: Immunological and pathological consequences of coxsackievirus rna persistence in the heart. Virology 2017;512:104-112.

5 Muir P: The association of enteroviruses with chronic heart-disease. Rev Med Virol 1992;2:9-18. 


\section{Cellular Physiology Cell Physiol Biochem 2019;53:121-140 \begin{tabular}{ll|l|l|}
\hline DOl: $10.33594 / 000000125$ & O 2019 The Author(s). Published by \\
and Biochemistry
\end{tabular} \\ \begin{tabular}{l|l} 
Published online: 24 June 2019 & Cell Physiol Biochem Press GmbH\&Co. KG \\
\hline
\end{tabular} \\ Peischard et al.: CVB3 Host Cell Interaction}

6 Sainani GS, Dekate MP, Rao CP: Heart-disease caused by coxsackie virus-b infection. Brit Heart J 1975;37:819-823.

7 Chau DHW, Yuan J, Zhang HF, Cheung P, Lim T, Liu Z, Sall A, Yang DC: Coxsackievirus b3 proteases 2a and 3c induce apoptotic cell death through mitochondrial injury and cleavage of eif4gi but not dap5/p97/nat1. Apoptosis 2007;12:513-524.

8 Buenz EJ, Howe CL: Picornaviruses and cell death. Trends Microbiol 2006;14:28-36.

9 Wu H, Zhai X, Chen Y, Wang RX, Lin LX, Chen SJ, Wang TY, Zhong XY, Wu XY, Wang Y, Zhang FM, Zhao WR, Zhong ZH: Protein $2 \mathrm{~b}$ of coxsackievirus b3 induces autophagy relying on its transmembrane hydrophobic sequences. Viruses 2016;8:131.

10 Maghsoudi N, Tafreshi NK, Khodagholi F, Zakeri Z, Esfandiarei M, Hadi-Alijanvand H, Sabbaghian M, Maghsoudi AH, Sajadi M, Zohri M, Moosavi M, Zeinoddini M: Targeting enteroviral 2a protease by a 16mer synthetic peptide: Inhibition of $2 \mathrm{a}$ (pro)-induced apoptosis in a stable tet-on hela cell line. Virology 2010;399:39-45.

11 Moreland RB, Garcea RL: Characterization of a nuclear-localization sequence in the polyomavirus capsid protein vp1. Virology 1991;185:513-518.

12 Abaitua F, Hollinshead M, Bolstad M, Crump CM, O'Hare P: A nuclear localization signal in herpesvirus protein vp1-2 is essential for infection via capsid routing to the nuclear pore. J Virol 2012;86:8998-9014.

13 Wang TY, Yu BH, Lin LX, Zhai X, Han YL, Qin Y, Guo ZW, Wu S, Zhong XY, Wang Y, Tong L, Zhang FM, Si XN, Zhao WR, Zhong ZH: A functional nuclear localization sequence in the vp1 capsid protein of coxsackievirus b3. Virology 2012;433:513-521.

14 Feuer R, Mena I, Pagarigan RR, Hassett DE, Whitton JL: Coxsackievirus replication and the cell cycle: A potential regulatory mechanism for viral persistence/latency. Med Microbiol Immun 2004;193:83-90.

15 Feuer R, Whitton JL: Preferential coxsackievirus replication in proliferating/activated cells: Implications for virus tropism, persistence, and pathogenesis. Curr Top Microbiol 2008;323:149-173.

16 Campanella M, de Jong AS, Lanke KWH, Melchers WJG, Willems PHGM, Pinton P, Rizzuto R, van Kuppeveld FJM: The coxsackievirus $2 \mathrm{~b}$ protein suppresses apoptotic host cell responses by manipulating intracellular ca2+ homeostasis. J Biol Chem 2004;279:18440-18450.

17 de Jong AS, Visch HJ, De Mattia F, van Dommelen MM, Swarts HG, Luyten T, Callewaert G, Melchers WJ, Willems PH, van Kuppeveld FJ: The coxsackievirus 2b protein increases efflux of ions from the endoplasmic reticulum and golgi, thereby inhibiting protein trafficking through the golgi. J Biol Chem 2006;281:14144-14150.

18 van Kuppeveld FJM, Galama JMD, Zoll J, Melchers WJG: Genetic-analysis of a hydrophobic domain of coxsackie b3 virus protein $2 \mathrm{~b}$ - a moderate degree of hydrophobicity is required for a cis- acting function in viral-rna synthesis. J Virol 1995;69:7782-7790.

19 van Kuppeveld FJM, Galama JMD, Zoll J, van den Hurk PJJC, Melchers WJG: Coxsackie b3 virus protein 2b contains a cationic amphipathic helix that is required for viral rna replication. J Virol 1996;70:3876-3886.

20 Lytton J, Westlin M, Hanley MR: Thapsigargin inhibits the sarcoplasmic or endoplasmic- reticulum caatpase family of calcium pumps. J Biol Chem 1991;266:17067-17071.

21 van Kuppeveld FJM, Hoenderop JGJ, Smeets RLL, Willems PHGM, Dijkman HBPM, Galama JMD, Melchers WJG: Coxsackievirus protein $2 \mathrm{~b}$ modifies endoplasmic reticulum membrane and plasma membrane permeability and facilitates virus release. Embo J 1997;16:3519-3532.

22 de Jong AS, Wessels E, Dijkman HBPM, Galama JMD, Melchers WJG, Willems PHGM, van Kuppeveld FJM: Determinants for membrane association and permeabilization of the coxsackievirus $2 \mathrm{~b}$ protein and the identification of the golgi complex as the target organelle. J Biol Chem 2003;278:1012-1021.

23 Cai ZJ, Shen L, Ma H, Yang J, Yang D, Chen H, Wei J, Lu QL, Wang DW, Xiang MX, Wang JA: Involvement of endoplasmic reticulum stress-mediated c/ebp homologous protein activation in coxsackievirus b3-induced acute viral myocarditis. Circ Heart Fail 2015;8:809-818.

24 Kim SH, Kwon DY, Kwak JH, Lee S, Lee YH, Yun J, Son TG, Jung YS: Tunicamycin-induced er stress is accompanied with oxidative stress via abrogation of sulfur amino acids metabolism in the liver. Int J Mol Sci 2018;19:pii:E4114.

25 Zhang L, Wang YM: Tauroursodeoxycholic acid alleviates h2o2-induced oxidative stress and apoptosis via suppressing endoplasmic reticulum stress in neonatal rat cardiomyocytes. Dose Response 2018;16:1559325818782631. 


\section{Cellular Physiology Cell Physiol Biochem 2019;53:121-140 \begin{tabular}{ll|l} 
and Biochemistry & $\begin{array}{l}\text { DOl: 10.33594/000000125 } \\
\text { Published online: } 24 \text { June 2019 }\end{array}$ & $\begin{array}{l}\text { O } 2019 \text { The Author(s). Published by } \\
\text { Cell Physiol Biochem Press GmbH\&Co. KG }\end{array}$ \\
\cline { 2 - 3 }
\end{tabular} \\ Peischard et al.: CVB3 Host Cell Interaction}

26 Ebermann L, Piper C, Kuhl U, Klingel K, Schlattner U, Siafarikas N, Zeichhardt H, Schultheiss HP, Dorner A: Impact of myocardial inflammation on cytosolic and mitochondrial creatine kinase activity and expression. Basic Res Cardiol 2009;104:247-257.

27 Zhang H, Yue Y, Sun TL, Wu XJ, Xiong SD: Transmissible endoplasmic reticulum stress from myocardiocytes to macrophages is pivotal for the pathogenesis of cvb3-induced viral myocarditis. Sci Rep 2017;7:42162.

28 Onomoto K, Yoneyama M, Fung G, Kato H, Fujita T: Antiviral innate immunity and stress granule responses. Trends Immunol 2014;35:420-428.

29 Kedersha N, Cho MR, Li W, Yacono PW, Chen S, Gilks N, Golan DE, Anderson P: Dynamic shuttling of tia-1 accompanies the recruitment of mrna to mammalian stress granules. J Cell Biol 2000;151:1257-1268.

30 Wu S, Wang Y, Lin LX, Si XN, Wang TY, Zhong XY, Tong L, Luan Y, Chen Y, Li XY, Zhang FM, Zhao WR, Zhong $\mathrm{ZH}$ : Protease 2a induces stress granule formation during coxsackievirus b3 and enterovirus 71 infections. Virol J 2014;11:192.

31 Chawla G, Lin CH, Han A, Shiue L, Ares M, Black DL: Sam68 regulates a set of alternatively spliced exons during neurogenesis. Mol Cell Biol 2009;29:201-213.

32 Corbo C, Orru S, Salvatore F: Srp20: An overview of its role in human diseases. Biochem Bioph Res Co 2013;436:1-5.

33 Kedersha N, Chen S, Gilks N, Li W, Miller IJ, Stahl J, Anderson P: Evidence that ternary complex (eif2-gtptrna(i)(met))-deficient preinitiation complexes are core constituents of mammalian stress granules. Mol Biol Cell 2002;13:195-210.

34 Ventoso I, MacMillan SE, Hershey JWB, Carrasco L: Poliovirus 2a proteinase cleaves directly the eif-4g subunit of eif-4f complex. FEBS Lett 1998;435:79-83.

35 McInerney GM, Kedersha NL, Kaufman RJ, Anderson P, Liljestrom P: Importance of eif2 alpha phosphorylation assembly in alphavirus translation and stress granule regulation. Mol Biol Cell 2005;16:3753-3763.

36 Zhai X, Wu S, Lin LX, Wang TY, Zhong XY, Chen Y, Xu WZ, Tong L, Wang Y, Zhao WR, Zhong ZH: Stress granule formation is one of the early antiviral mechanisms for host cells against coxsackievirus b infection. Virol Sin 2018;33:314-322.

37 Liberman N, Gandin V, Svitkin YV, David M, Virgili G, Jaramillo M, Holcik M, Nagar B, Kimchi A, Sonenberg $\mathrm{N}$ : Dap5 associates with eif2 beta and eif4ai to promote internal ribosome entry site driven translation. Nucleic Acids Res 2015;43:3764-3775.

38 Lewis SM, Cerquozzi S, Graber TE, Ungureanu NH, Andrews M, Holcik M: The eif4g homolog dap5/ p97 supports the translation of select mrnas during endoplasmic reticulum stress. Nucleic Acids Res 2008;36:168-178.

39 Hanson PJ, Ye X, Qiu Y, Zhang HM, Hemida MG, Wang F, Lim T, Gu A, Cho B, Kim H, Fung G, Granville DJ, Yang D: Cleavage of dap5 by coxsackievirus b3 2a protease facilitates viral replication and enhances apoptosis by altering translation of ires-containing genes. Cell Death Differ 2016;23:828-840.

40 Guo RY, Gu JK, Zong S, Wu M, Yang MJ: Structure and mechanism of mitochondrial electron transport chain. Biomed J 2018;41:9-20.

41 Jonckheere AI, Smeitink JAM, Rodenburg RJT: Mitochondrial atp synthase: Architecture, function and pathology. J Inherit Metab Dis 2012;35:211-225.

42 Ebermann L, Wika S, Klumpe I, Hammer E, Klingel K, Lassner D, Volker U, Erben U, Zeichhardt H, Schultheiss HP, Dorner A: The mitochondrial respiratory chain has a critical role in the antiviral process in coxsackievirus b3-induced myocarditis. Lab Invest 2012;92:125-134.

43 Huang G, Chen Y, Lu H, Cao X: Coupling mitochondrial respiratory chain to cell death: An essential role of mitochondrial complex i in the interferon-beta and retinoic acid-induced cancer cell death. Cell Death Differ 2007;14:327-337.

44 Xie B, Zhou JF, Lu Q, Li CJ, Chen P: Oxidative stress in patients with acute coxsackie virus myocarditis. Biomed Environ Sci 2002;15:48-57.

45 Xu J, Nie HG, Zhang XD, Tian Y, Yu B: Down-regulated energy metabolism genes associated with mitochondria oxidative phosphorylation and fatty acid metabolism in viral cardiomyopathy mouse heart. Mol Biol Rep 2011;38:4007-4013.

46 Helluy X, Sauter M, Ye YX, Lykowsky G, Kreutner J, Yilmaz A, Jahns R, Boivin V, Kandolf R, Jakob PM, Hiller $\mathrm{KH}$, Klingel K: In vivo $2{ }^{*}$ weighted mri visualizes cardiac lesions in murine models of acute and chronic viral myocarditis. Plos One 2017;12:e0172084. 


\section{Cellular Physiology Cell Physiol Biochem 2019;53:121-140

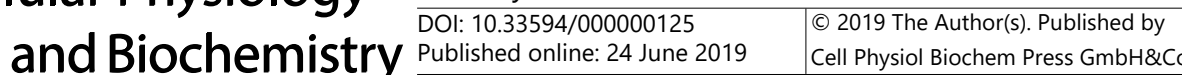 \\ Peischard et al.: CVB3 Host Cell Interaction}

47 Bruneau BG: Signaling and transcriptional networks in heart development and regeneration. Cold Spring Harb Perspect Biol 2013;5:a008292.

48 Lin L, Zhang M, Yan R, Shan H, Diao JY, Wei J: Inhibition of drp1 attenuates mitochondrial damage and myocardial injury in coxsackievirus b3 induced myocarditis. Biochem Biophys Res Commun 2017;484:550-556.

49 Lackner LL, Nunnari J: Small molecule inhibitors of mitochondrial division: Tools that translate basic biological research into medicine. Chem Biol 2010;17:578-583.

50 Maze SS, Adolph RJ: Myocarditis - unresolved issues in diagnosis and treatment. Clin Cardiol 1990;13:69-79.

51 Steinke K, Sachse F, Ettischer N, Strutz-Seebohm N, Henrion U, Rohrbeck M, Klosowski R, Wolters D, Brunner S, Franz WM, Pott L, Munoz C, Kandolf R, Schulze-Bahr E, Lang F, Klingel K, Seebohm G: Coxsackie virus b3 modulates cardiac ion channels. FASEB J 2013;27:4108-4121.

52 Salerno F, Girerd N, Chalabreysse L, Billaud G, Lina B, Chevalier P: Myocarditis and cardiac channelopathies: A deadly association? Int J Cardiol 2011;147:468-470.

53 Piccini I, Fehrmann E, Frank S, Muller FU, Greber B, Seebohm G: Adrenergic stress protection of human ips cell-derived cardiomyocytes by fast k(v)7.1 recycling. Front Physiol 2017;8:705.

54 Seebohm G, Strutz-Seebohm N, Ureche ON, Henrion U, Baltaev R, Mack AF, Korniychuk G, Steinke K, Tapken D, Pfeufer A, Kaab S, Bucci C, Attali B, Merot J, Tavare JM, Hoppe UC, Sanguinetti MC, Lang F: Long qt syndrome-associated mutations in kcnq1 and kcne1 subunits disrupt normal endosomal recycling of $\mathrm{i}(\mathrm{ks})$ channels. Circ Res 2008;103:1451--1457.

55 Wessely R, Klingel K, Santana LF, Dalton N, Hongo M, Lederer WJ, Kandolf R, Knowlton KU: Transgenic expression of replication-restricted enteroviral genomes in heart muscle induces defective excitationcontraction coupling and dilated cardiomyopathy. J Clin Invest 1998;102:1444-1453.

56 Kaese S, Larbig R, Rohrbeck M, Frommeyer G, Dechering D, Olligs J, Schonhofer-Merl S, Wessely R, Klingel $\mathrm{K}$, Seebohm G, Eckardt L: Electrophysiological alterations in a murine model of chronic coxsackievirus b3 myocarditis. Plos One 2017;12:e0180029. 